\title{
More than one way to skin a cat
}

\author{
George J. Magovern, Jr, MD
}

\author{
From the Department of Thoracic and Cardiovascular Surgery, Allegheny Health Network, Drexel University \\ College of Medicine, Pittsburgh, Pa. \\ Disclosures: Dr Magovern serves on the Board of Directors of Cardiac Assist, Inc. \\ Received for publication Nov 11, 2015; accepted for publication Nov 12, 2015. \\ Address for reprints: George J. Magovern, Jr, MD, Department of Thoracic and Cardiovascular Surgery, Drexel \\ University College of Medicine, Allegheny Health Network, 320 East North Ave, 14th Floor, South Tower, \\ Pittsburgh, PA 15212 (E-mail: gmagover@wpahs.org). \\ J Thorac Cardiovasc Surg 2016;151:e77-8 \\ $0022-5223 / \$ 36.00$ \\ Copyright (c) 2016 by The American Association for Thoracic Surgery \\ http://dx.doi.org/10.1016/j.jtcvs.2015.11.020
}

The case report by Samuels and colleagues ${ }^{1}$ is intriguing, offering an alternative to veno-arterial (VA) extracorporeal membrane oxygenation (ECMO) for cardiopulmonary shock, namely veno-veno (VV) ECMO and an Impella 5.0 left ventricular assist device (LVAD) (Abiomed, Danvers, Mass). ${ }^{1}$ VA ECMO remains the ultimate safety net for patients in shock because it is quick and simple to deploy; however, it does not unload the left ventricle, and often increases wall tension. In addition, it does not uncouple the recovery of cardiac and pulmonary failure. If cardiac and pulmonary function do not promptly improve, mortality with VA ECMO rapidly approaches $100 \%$ after 2 to 3 days. ${ }^{2}$ Short of a full cardiopulmonary arrest, LVAD insertion coupled with VV ECMO may salvage patients who might otherwise die of multisystem failure on VA ECMO.

In the case reported by Samuels and colleagues, the patient was first treated with the Impella 5.0 LVAD, which restored adequate cardiac output. Shortly thereafter, however, the patient developed refractory pulmonary failure with severe hypoxia and hypercarbia. Instead of converting to VA ECMO, the authors instituted VV ECMO. The patient was successfully weaned from both devices, but required 2 weeks of cardiac support and 3 weeks of pulmonary support, underscoring the severity of the patient's initial clinical shock state.

The right axillary Impella implant allowed for a short distance from the inflow tip to the insertion sight, thereby reducing the risk of catheter dislodgement. The introduction of 2 commercially available dual-lumen cannulas, the Avalon cannula (Avalon, Rancho Dominquez, Calif) and the Protek Duo (Cardiac Assist, Pittsburgh, Pa), have made VV ECMO insertion quite straightforward. Whereas traditional 2-cannula VV ECMO circuits can be deployed at the bedside, both the Avalon and the Protek Duo must be inserted with either fluoroscopy or transesophageal echocardiography (TEE) guidance. With the Avalon device, deoxygenated blood is drained from the inferior and superior vena cavae to the ECMO circuit, and oxygenated blood is then returned to the right atrium. With the Protek Duo device, deoxygenated blood is drained through the

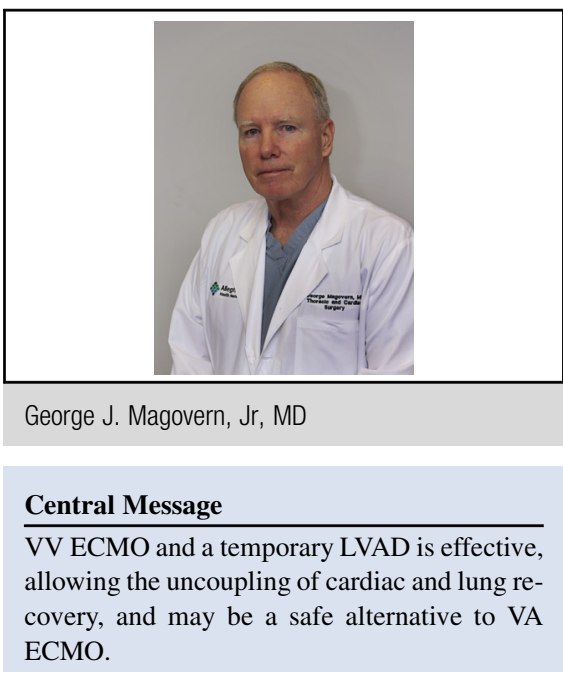

See Article page e75.

superior vena cava to the ECMO circuit and then pumped into the main pulmonary artery. The Protek Duo cannula has the advantage of bypassing the right ventricle, and thus can be used for right ventricular support in patients with right ventricular failure.

This report is most encouraging, because the patient survived without multisystem failure with 2 weeks of LVAD support and 3 weeks of VV ECMO. Over the past decade, VV ECMO has emerged as safe and reliable support for acute respiratory distress syndrome (ARDS), with well over 200 centers performing more than 4000 adult cases with a survival rate of at least $60 \%$. $^{3}$ Although the authors note that case reports on combining the Impella LVAD with VA ECMO to decompress the left ventricle have reported survivors, ${ }^{4,5}$ there are other patients who have experienced profound and persistent respiratory failure not due to pulmonary edema per se, who require more than left ventricular decompression to wean from VA ECMO.

Because revascularization and pharmacologic therapies have not dramatically impacted the high mortality rates of patients in cardiogenic shock, the 2015 Expert Consensus Statement on the Use of Percutaneous Mechanical Circulatory Support Devices in Cardiovascular Care has endorsed a number of new devices, including axial flow pumps, such as the Impella LVAD; left atrial-to-femoral artery bypass pumps, specifically the Tandem Heart; and new devices for institution of ECMO, such as Avalon and Protek Duo. This case report is important, because it underscores that registries and randomized controlled trials comparing 
different strategies in different clinical scenarios are needed to determine whether this case report is simply an isolated success or heralds a reliable alternative to VA ECMO.

\section{References}

1. Samuels L, Gnall E, Casanova-Ghosh E, Plestis K. A hybrid configuration of a left ventricular assist device and veno-venous extracorporeal membrane oxygenation. J Thorac Cardiovasc Surg. 2016;151:e75-6.

2. Magovern GJ Jr, Simpson KA. Extracorporeal membrane oxygenation for adult cardiac failure: the Allegheny General Hospital experience. Ann Thorac Surg. 1999;68:655-61.
3. Moraca R, Magovern GJ Jr. Extracorporeal membrane oxygenation for respiratory failure in adults. In: Cameron J, Cameron S, eds. Current Surgical Therapy. 11th ed. Philadelphia: Saunders; 2013.

4. Koeckert MS, Jorde UP, Naka Y, et al. Impella LP 2.5 for left ventricular uploading during venoarterial extracorporeal membrane oxygenation support. J Card Surg. 2011;26:666-76.

5. Cheng A, Swartz MF, Massey HT. Impella to unload the left ventricle during peripheral extracorporeal membrane oxygenation. ASAIO J. 2013;59: 533-6.

6. Rihal CS, Naidu SS, Givertz MM, Szeto WY, Burke JA, Kapur NK, et al. 2015 SCAI/ACC/HFSA/STS clinical expert consensus statement on the use of percutaneous mechanical circulatory support devices in cardiovascular care. J Am Coll Cardiol. 2015;65:e7-26. 